\title{
Totally endoscopic mitral valve repair using a three-dimensional endoscope system: initial clinical experience in Korea
}

\author{
Jihoon $\mathrm{Kim}^{1}$, Jae Suk Yoo ${ }^{2}$ \\ ${ }^{1}$ Department of Thoracic and Cardiovascular Surgery, Kangnam Sacred Heart Hospital, Hallym University Medical Center, Hallym University \\ College of Medicine, Seoul, Republic of Korea; ${ }^{2}$ Department of Thoracic and Cardiovascular Surgery, Sejong General Hospital, Bucheon, Gyeonggi- \\ do, Republic of Korea \\ Contributions: (I) Conception and design: JS Yoo; (II) Administrative support: JS Yoo; (III) Provision of study materials or patients: JS Yoo; (IV) \\ Collection and assembly of data: JS Yoo; (V) Data analysis and interpretation: J Kim; (VI) Manuscript writing: All authors; (VII) Final approval of \\ manuscript: All authors. \\ Correspondence to: Jae Suk Yoo, MD, PhD. Department of Thoracic and Cardiovascular Surgery, Sejong General Hospital, 28,489 gil Hohyen-ro \\ Bucheon-si, Gyeonggi-do 14754, Republic of Korea. Email: mdyoo77@gmail.com.
}

\begin{abstract}
Background: The lack of depth perception is a significant challenge in two-dimensional (2D) videoassisted/directed minimally invasive cardiac surgery (MICS). Accordingly, restoration of stereoscopic vision is potentially beneficial, and we present a single center experience of a three-dimensional (3D) endoscope system in cardiac surgery without robotic assistance.

Methods: We retrospectively reviewed the initial 40 consecutive patients who received totally endoscopic mitral valve (MV) repair using a 3D endoscope system between September 2017 and April 2019. The preoperative characteristics, operative data, and immediate postoperative outcomes, including echocardiographic results, were investigated.

Results: In all the patients ( $\mathrm{n}=40,100 \%)$, successful MV repair using the standard repair techniques was achieved regardless of the location of the MV lesion as follows: anterior leaflet $(n=8,20.0 \%)$, posterior leaflet $(\mathrm{n}=15,37.5 \%)$, and both leaflets $(\mathrm{n}=17,42.5 \%)$. Concomitant tricuspid ring annuloplasty $(\mathrm{n}=9,22.5 \%)$ and atrial fibrillation ablation $(n=7,17.5 \%)$ were performed. There was no mortality. One reoperation for bleeding occurred. One patient had a sternotomy conversion due to aortic dissection immediately after declamping. Postoperative mitral regurgitation (MR) grades were none or trace in 38 patients (95.0\%) and mild in 2 patients $(5.0 \%)$ on predischarge echocardiography.

Conclusions: Totally endoscopic MV repair using a 3D endoscope system is technically feasible and safe on the basis of this initial experience.
\end{abstract}

Keywords: Mitral valve regurgitation; minimally invasive cardiac surgery (MICS); mitral valve repair; 3D videoscope

Submitted Aug 01, 2019. Accepted for publication Dec 13, 2019.

doi: $10.21037 /$ jtd.2019.12.126

View this article at: http://dx.doi.org/10.21037/jtd.2019.12.126

\section{Introduction}

Median sternotomy is the gold standard in cardiac surgery owing to its excellent exposure of cardiac structures. Meanwhile, the current trend of using minimally invasive approaches in the field of surgery has influenced cardiac surgery, and substantial minimally invasive cardiac surgery (MICS) techniques and dedicated surgical instruments have been developed over the last two decades.

In mitral valve (MV) repair surgery, the right minithoracotomy approach offers a good view directly facing the atrial side of the MV leaflets without excessive 


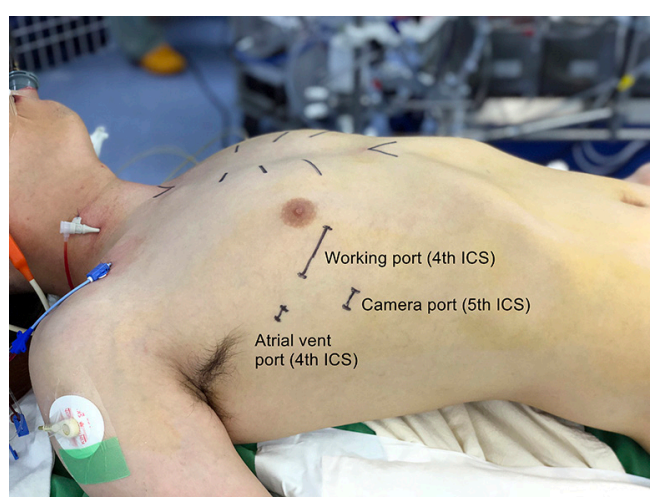

Figure 1 Port placement for the totally endoscopic mitral valve repair. ICS, intercostal space.

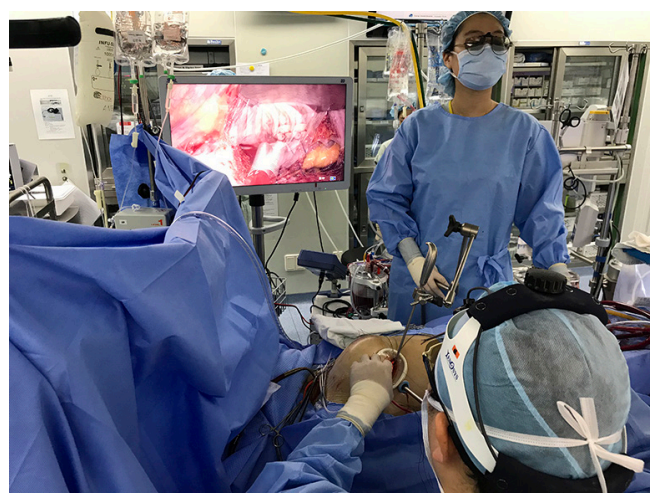

Figure 2 Intraoperative surgical field.

atrial retraction. Rib spreading, however, is mandatory for direct vision of the $M V$ and instrumentation, which causes considerable postoperative pain. To avoid this, a non-ribspreading strategy using a two-dimensional (2D) endoscope system is adopted in numerous institutions worldwide. Despite the great visibility with magnification, the operator lacks the depth perception with the $2 \mathrm{D}$ endoscopic view. This is a major challenge of the $2 \mathrm{D}$ endoscopic surgery, which might raise the entry barriers for cardiac surgeons. In this context, restoration of stereoscopic vision is potentially beneficial and could be achieved with the three-dimensional (3D) endoscopic system.

The aim of this study was to evaluate the feasibility and safety of the 3D endoscopic system in totally endoscopic MV repair without robotic assistance by reviewing initial cases in Korean populations.

\section{Methods}

\section{Patients}

From September 2017 to April 2019, 87 patients underwent totally endoscopic cardiac surgery using the $3 \mathrm{D}$ endoscope system (IMAGE1 S 3D full-HD Video Endoscope System, KARL STORZ SE \& Co. KG, Tuttlingen, Germany) with passive polarized 3D glasses at Sejong General Hospital, Bucheon-si, Gyeonggi-do, South Korea. Among these patients, 40 subjects underwent $M V$ repair with or without concomitant cardiac procedures (atrial fibrillation ablation surgery and tricuspid annuloplasty) and therefore constituted the study population.

For the MICS approach, we excluded patients with contraindications for peripheral cannulation (e.g., peripheral vascular disease and aortic pathology), suspected right pleural adhesion (including history of previous right thoracic surgery), and need for additional aortic valve procedure and/or coronary artery bypass grafting.

A surgeon (JSY) carefully reviewed the patients, held a discussion with the patients, and performed the surgery. The authors retrospectively reviewed perioperative characteristics and early outcomes.

\section{Operative technique}

Conventional general anesthesia with double-lumen endotracheal intubation and single left lung ventilation was used in all the patients. A transesophageal echocardiographic (TEE) probe was inserted, and external defibrillator patches were attached on the back. After inserting a 5-Fr introducer sheath (Radiofocus Introducer II, Terumo Medical Corp., Tokyo, Japan) for the later superior vena cava cannulation through the right internal jugular vein, the patients were positioned supine with the right chest elevated approximately $30^{\circ}$. After sterile draping, a 4-cm minithoracotomy incision (working port) was made in the right fourth intercostal space (ICS) in the anterior- to mid-axillary line along the submammary crease. A soft tissue retractor (Alexis Wound Protector/Retractor, Applied Medical Resources Group, CA, USA) was placed, and no rib spreader was used. A separate 5-mm incision was made posterior to the working port for the sump catheter insertion, and a 10-mm trocar was inserted in the fifth ICS on the midaxillary line for the endoscope (Figures 1,2). 
A $30^{\circ}$-angled $3 \mathrm{D}$ endoscope was set and operated by an assistant. The chest cavity was flooded with carbon dioxide gas. Cardiopulmonary bypass $(\mathrm{CPB})$ was established by cannulating the right internal jugular vein and femoral vessels with the percutaneous Seldinger technique or with a 2-cm-long oblique groin incision. When the femoral artery was cannulated percutaneously, two percutaneous suture devices (Perclose Proglide, Abbott Laboratories, Chicago, IL, USA) were used for closure. Vacuum-assisted venous drainage was used during $\mathrm{CPB}$, and the pericardium was opened longitudinally $3 \mathrm{~cm}$ anterior to the phrenic nerve. An aortic root cannula was inserted, and the aorta was cross-clamped with a Glauber aortic clamp (Cardiomedical $\mathrm{GmbH}$, Langenhagen, Germany) through the working port. Then, an antegrade, single-dose, modified del Nido cardioplegia was used for the myocardial protection. The $M V$ was exposed through the interatrial groove using the Adams-Yozu left atrial retractor (Geister, Tuttingen, Germany) and standard mitral repair techniques were utilized.

In patients who required right atriotomy for concomitant procedures, the vena cavae were clamped with bulldog clamps. Tricuspid regurgitation was corrected by placing an annuloplasty ring (Tri-Ad Adams Annuloplasty Band, Medtronic, Minneapolis, MN, USA), and atrial fibrillation ablation lesions were created with a cryothermy probe (Cryoflex, Medtronic, Minneapolis, MN, USA). The cryoablation lesion set was described in a previous study (1).

The result of the valve repair was evaluated with intraoperative TEE after weaning from the CPB. The two stab incision sites were used for chest tube insertion, and the working port incision was closed in the customary manner.

\section{Definitions}

The primary outcomes of interest were early death ( $<30$ days after the index surgery), hospital stay duration, and major postoperative complications (reoperations for bleeding, acute renal failure requiring dialysis, low cardiac output syndrome, stroke, thromboembolic event, surgical wound problem, permanent pacemaker insertion, and pneumonia). Postoperative transthoracic echocardiography (TTE) was performed in all the patients before discharge.

\section{Statistical analysis}

Categorical variables were presented as frequencies and percentages. Continuous variables were expressed as mean \pm standard deviation or medians with ranges. All statistical analyses were performed using SPSS version 24.0 (IBM, Armonk, NY, USA).

\section{Ethics statement}

The present research protocol was reviewed and approved by the institutional review board of Sejong General Hospital, which waived the requirement to obtain informed consent owing to the retrospective nature of the study.

\section{Results}

The baseline profiles of the 40 patients are listed in Table 1. The median age was 55 years (interquartile range, 45-59 years), and 7 patients had atrial fibrillation. On the preoperative echocardiography, $92.5 \%$ of patients had severe mitral regurgitation (MR) and the rest of them had moderate-to-severe MR. The prolapsing leaflets were anterior only in 8 patients, posterior only in 15 patients, and both anterior and posterior in 17 patients. The etiology of the $M V$ was degenerative disease in all patients except in one, which was infective endocarditis.

Table 2 summarizes the operative data. MV repair was successfully performed in all the patients $(n=40,100 \%)$ without conversion to MV replacement. Various standard MV repair techniques were used with no limitations in regard to the diseased leaflet location. Mitral ring annuloplasties were performed in 39 patients except one who had a very small mitral annulus. Associated procedures were conducted in 10 patients as follows: concomitant tricuspid ring annuloplasty and atrial fibrillation ablation in 7 patients, solitary tricuspid annuloplasty in 2 patients, and ascending aorta replacement after sternotomy conversion due to ascending aortic dissection after declamping in one patient. The mean $\mathrm{CPB}$ and aortic cross-clamping times were $176.1 \pm 41.7$ and $116.3 \pm 33.9$ minutes, respectively.

None of the patients had an operative mortality (Table 3). Except for 1 reoperation for bleeding from the aortic root cannula site, no immediate postoperative complications occurred. Postoperative and predischarge TTE was performed on postoperative day 5 (5.0 \pm 0.8 days; Table 4). Residual MR grade was none or trace in 38 patients $(95.0 \%)$ and mild in 2 patients (5.0\%). None of the patients needed reoperation for residual MR grades indicating moderate or severe residual disease. 
Table 1 Baseline patient profiles $(\mathrm{n}=40)$

\begin{tabular}{|c|c|}
\hline Characteristics & $\mathrm{n}(\%)$ or mean $\pm \mathrm{SD}$ \\
\hline \multicolumn{2}{|l|}{ Demography } \\
\hline Male & $25(62.5)$ \\
\hline Age (years), median (interquartile range) & 55 [45-59] \\
\hline Body surface area $\left(\mathrm{m}^{2}\right)$ & $1.68 \pm 0.34$ \\
\hline \multicolumn{2}{|l|}{ Clinical data } \\
\hline NYHA Fc III or IV & $9(22.5)$ \\
\hline Atrial fibrillation & $7(17.5)$ \\
\hline Hypertension & $13(32.5)$ \\
\hline Diabetes mellitus & $3(7.5)$ \\
\hline History of stroke & $3(7.5)$ \\
\hline Chronic obstructive pulmonary disease & $0(0.0)$ \\
\hline Chronic kidney disease & $3(7.5)$ \\
\hline Previous sternotomy & $3(7.5)$ \\
\hline \multicolumn{2}{|l|}{ Echocardiographic data } \\
\hline LV ejection fraction (\%) & $59.7 \pm 5.5$ \\
\hline LV systolic dimension (mm) & $35.8 \pm 7.1$ \\
\hline LV diastolic dimension (mm) & $57.6 \pm 6.2$ \\
\hline LA dimension (mm) & $47.4 \pm 7.1$ \\
\hline Tricuspid regurgitation grade $(>2+)$ & $3(7.5)$ \\
\hline $\mathrm{RV}-\mathrm{RA} \Delta \mathrm{P}(\mathrm{mmHg})$ & $28.9 \pm 13.0$ \\
\hline \multicolumn{2}{|l|}{ Mitral regurgitation grade } \\
\hline Severe & $37(92.5)$ \\
\hline Moderate to severe & $3(7.5)$ \\
\hline \multicolumn{2}{|l|}{ Mitral valve leaflet prolapse subsets } \\
\hline Anterior leaflet & $8(20.0)$ \\
\hline Posterior leaflet & $15(37.5)$ \\
\hline Bileaflet & $17(42.5)$ \\
\hline \multicolumn{2}{|l|}{ Cause of mitral regurgitation } \\
\hline Degenerative & $39(97.5)$ \\
\hline Rheumatic & $0(0.0)$ \\
\hline Infective endocarditis & $1(2.5)$ \\
\hline
\end{tabular}

NYHA Fc, New York Heart Association Functional Class; LV, left ventricle; LA, left atrium; RV-RA $\triangle \mathrm{P}$, right ventricular-right atrial pressure gradient.
Table 2 Operative characteristics $(\mathrm{n}=40)$

\begin{tabular}{lc}
\hline Characteristics & $\mathrm{n}(\%)$ or mean \pm SD \\
\hline Mitral repair procedure & $39(97.5)$ \\
Ring annuloplasty & $24(60.0)$ \\
Neochordae implantation & $13(32.5)$ \\
Commissuroplasty & $8(20.0)$ \\
Leaflet plication & $9(22.5)$ \\
Indentation closure & $5(12.5)$ \\
Triangular/quadrangular resection & \\
Leaflet manipulation & $7(17.5)$ \\
Anterior leaflet & $19(47.5)$ \\
Posterior leaflet & $14(35.0)$ \\
Bileaflet & \\
Concomitant procedures & $9(22.5)$ \\
Tricuspid annuloplasty & $7(17.5)$ \\
Atrial fibrillation ablation & $176.1 \pm 41.7$ \\
Ascending aorta replacement & \\
Cardiopulmonary bypass time (min) & $116.3 \pm 33.9$ \\
Aortic cross-clamping time (min) & \\
\hline performed after sternotomy conversion & \\
\hline
\end{tabular}

${ }^{\text {a }}$, performed after sternotomy conversion for aortic dissection detected on the operative field.

\section{Discussion}

MICS, including robot-assisted cardiac surgeries, are gaining popularity worldwide with growing evidence of its feasibility, safety, and durability (2). For the MV repair, right-side thoracotomy or port access offers excellent exposure, that is, "the en face view," without distorting the natural anatomy, so that the operator can evaluate the valve pathology and repair result in the virtually normal anatomical position of the heart.

The first step of MICS MV repair is the right minithoracotomy approach with direct vision (3). This needs an approximately 6-cm-long anterolateral submammary skin incision and rib spreading mostly at the fourth ICS. With this approach, however, visualization and illumination of the deep-seated subvalvular apparatus are often troublesome; therefore, a thoracoscope is frequently 
Table 3 Postoperative outcomes and complications $(n=40)$

\begin{tabular}{lc}
\hline Characteristics & $\mathrm{n}(\%)$ or mean \pm SD \\
\hline Early death (<30 days) & $0(0)$ \\
Ventilation time (hours) & $4.1 \pm 1.7$ \\
ICU stay (hours) & $18.9 \pm 2.7$ \\
Hospital stay (days, interquartile range) & $7[7-7]$ \\
Complications & \\
Reoperations for bleeding & $1(2.5)$ \\
ARF requiring dialysis & $0(0.0)$ \\
Low cardiac output syndrome & $0(0.0)$ \\
Stroke & $0(0.0)$ \\
Thromboembolic event & $0(0.0)$ \\
Thoracotomy wound & $0(0.0)$ \\
Groin wound & $0(0.0)$ \\
Permanent pacemaker insertion & $0(0.0)$ \\
Pneumonia & $0(0.0)$ \\
Sternotomy conversion* & $1(2.5)$ \\
Reoperation for MR & $0(0.0)$ \\
\hline
\end{tabular}

*, iatrogenic acute type A aortic dissection (cross-clamping site). ICU, intensive care unit; ARF, acute renal failure; MR, mitral regurgitation.

used for the assistant visualization. Installing a camera provides the same "surgeon's view" on monitors to all the personnel in the operating room, which definitely helps them to assist the surgeon, and is also educational. Presentation of the surgical process also facilitates good communication with anesthetists and pump staff (4).

Rib spreading, on the other hand, causes significant postoperative pain and might induce rib fracture, or intercostal vessel/nerve injury. To avert these potential risks, totally endoscopic surgery without rib spreading could be performed with a $2 \mathrm{D}$ thoracoscope. Casselman et al. (5) reported that $93.5 \%$ of the patients experienced minimal to almost no procedure-related pain with excellent cosmesis with non-rib-spreading surgery. Despite the many advantages of using a 2D scope, the lack of stereoscopic vision is a major drawback, which impedes the quicker and natural movement of the operator.

In 1998, the first successful robotic cardiac surgery was performed with the advent of the robotic telemanipulation surgical system with a 3D camera, the da Vinci surgical system (Intuitive Surgical, Inc., Sunnyvale, CA, USA) (6).
Table 4 Postoperative echocardiographic findings ( $n=40)$

\begin{tabular}{lc}
\hline Variable & $\mathrm{n}(\%)$ or mean $\pm \mathrm{SD}$ \\
\hline Days after the operation & $5.0 \pm 0.8$ \\
MR & $38(95.0)$ \\
None or trace & $2(5.0)$ \\
Mild & $0(0.0)$ \\
Moderate or severe & \\
TR & $33(82.5)$ \\
None or trace & $7(17.5)$ \\
Mild & $0(0.0)$ \\
Moderate or severe & $51.4 \pm 7.9$ \\
LV ejection fraction (\%) & $34.1 \pm 6.2$ \\
LV systolic dimension (mm) & $48.6 \pm 5.7$ \\
LV diastolic dimension (mm) & $40.9 \pm 7.0$ \\
LA dimension (mm) & $20.2 \pm 4.4$ \\
RV-RA $\triangle \mathrm{P}$ (mmHg) & \\
\hline MR, mitral regurgitation; TR, tricuspid regurgitation; ARF, acute \\
renal failure; LV, left ventricular; LA, left atrial; RV-RA $\Delta \mathrm{P}$, right \\
ventricular-right atrial pressure gradient. & \\
&
\end{tabular}

This system provides high-quality 3D visualization with magnification, which restores the stereoscopic vision, so that the surgeon can easily handle the instruments. In addition, the robotic system is equipped with multidirectional intracardiac instrument articulation, motion scaling, and tremor filtration functions (7). According to a recent Korean national database analysis, robotic cardiothoracic surgeries are increasing, and MV repair is the most commonly performed robotic cardiac surgery (8). Yoo et al. $(9,10)$ demonstrated operative feasibility and favorable outcomes of robotic MV repair by reviewing the initial Korean experiences. Long-term results after the robotic MV repair from the same institution also showed excellent outcomes (11).

Nonetheless, robotic arms need additional two or more incisions on the chest. The main disadvantage of this telemanipulation system is the lack of tactile feedback; thus, the surgeon depends solely on the "visual feedback" during surgery. Furthermore, the high price of the robotic system, limited number of robotic instrument uses, and the need for two surgeons, a console surgeon and a bedside surgeon, raise issues concerning human and financial resources.

In this regard, totally endoscopic MV repair with a $3 \mathrm{D}$ 
scope without robotic assistance (3D TEMVR) might be a rational option. After securing the $3 \mathrm{D}$ endoscope system and semi-permanent long-shaft MICS instruments, no additional surgeons or payment for the instruments is needed.

Basically, all the procedures in 3D endoscopic surgery are identical to those in direct vision and 2D endoscopic surgery; thus, no additional training is necessary. Accordingly, in our initial 3D TEMVR experiences, virtually all kinds of conventional MV repair techniques were feasible (Table 2).

Compared with robotic surgery, 3D TEMVR has a definite advantage of having direct tactile feedback in addition to a magnified stereoscopic vision. Obesity and an excessively deep thoracic cavity increase the level of difficulty of MICS for difficult handling of long-shafted instruments (12). Robotic surgery might be a superior option for these particular patients, but considering relatively thin body habitus in the Korean population, 3D TEMVR would be suitable in most cases.

According to a recent meta-analysis that compared between 2D and 3D laparoscopic and thoracoscopic surgeries, 3D endoscopic surgery showed a significantly shorter operating time, less blood loss, and shorter hospital stay (13). For MV repair, Westhofen et al. (14) reported less pain and shorter operation time with the $3 \mathrm{D}$ totally endoscopic approach without rib spreading than with the rib spreading surgery.

Meanwhile, researchers in various surgical fields have addressed the ergonomic issues regarding surgical $3 \mathrm{D}$ imaging. Common concerns were burning eyes, eye focusing, visual fatigue, visual adaptation of $3 \mathrm{D}$ to $2 \mathrm{D}$, discomforts, nausea, fatigue, and vertigo. These concerns, however, were not significant or relevant $(15,16)$.

This study has some limitations owing to retrospective single-institution small-volume observational study design without a control group. Only one surgeon performed the procedures; therefore, inter-operator differences could not be studied.

In conclusion, 3D TEMVR is technically feasible and safe, with excellent clinical outcomes and good cosmesis in this initial Korean experience. Further large-scale investigations, including long-term follow-up results, are warranted.

\section{Acknowledgments}

Funding: None.

\section{Footnote}

Conflicts of Interest: The authors have no conflicts of interest to declare.

Ethical Statement: The authors are accountable for all aspects of the work in ensuring that questions related to the accuracy or integrity of any part of the work are appropriately investigated and resolved. The present research protocol was reviewed and approved by the institutional review board of Sejong General Hospital, which waived the requirement to obtain informed consent owing to the retrospective nature of the study.

Open Access Statement: This is an Open Access article distributed in accordance with the Creative Commons Attribution-NonCommercial-NoDerivs 4.0 International License (CC BY-NC-ND 4.0), which permits the noncommercial replication and distribution of the article with the strict proviso that no changes or edits are made and the original work is properly cited (including links to both the formal publication through the relevant DOI and the license). See: https://creativecommons.org/licenses/by-nc-nd/4.0/.

\section{References}

1. Kim JB, Bang JH, Jung SH, et al. Left atrial ablation versus biatrial ablation in the surgical treatment of atrial fibrillation. Ann Thorac Surg 2011;92:1397-404; discussion 1404-5.

2. Modi P, Hassan A, Chitwood WR Jr. Minimally invasive mitral valve surgery: a systematic review and meta-analysis. Eur J Cardiothorac Surg 2008;34:943-52.

3. Loulmet DF, Carpentier A, Cho PW, et al. Less invasive techniques for mitral valve surgery. J Thorac Cardiovasc Surg 1998;115:772-9.

4. Ito T. Minimally invasive mitral valve surgery through right mini-thoracotomy: recommendations for good exposure, stable cardiopulmonary bypass, and secure myocardial protection. Gen Thorac Cardiovasc Surg 2015;63:371-8.

5. Casselman FP, Van Slycke S, Dom H, et al. Endoscopic mitral valve repair: feasible, reproducible, and durable. J Thorac Cardiovasc Surg 2003;125:273-82.

6. Carpentier A, Loulmet D, Aupècle B, et al. Computer assisted open heart surgery. First case operated on with success. C R Acad Sci III 1998;321:437-42.

7. Woo YJ, Seeburger J, Mohr FW. Minimally invasive valve 
surgery. Semin Thorac Cardiovasc Surg 2007;19:289-98.

8. Kang CH, Bok JS, Lee NR, et al. Current Trend of Robotic Thoracic and Cardiovascular Surgeries in Korea: Analysis of Seven-Year National Data. Korean J Thorac Cardiovasc Surg 2015;48:311-7.

9. Yoo JS, Kim JB, Jung SH, et al. Mitral durability after robotic mitral valve repair: analysis of 200 consecutive mitral regurgitation repairs. J Thorac Cardiovasc Surg 2014;148:2773-9.

10. Yoo JS, Kim JB, Jung SH, et al. Echocardiographic assessment of mitral durability in the late period following mitral valve repair: minithoracotomy versus conventional sternotomy. J Thorac Cardiovasc Surg 2014;147:1547-52.

11. Kim HJ, Kim JB, Jung SH, et al. Clinical outcomes of robotic mitral valve repair: a single-center experience in Korea. Ann Cardiothorac Surg 2017;6:9-16.

12. Davierwala PM, Seeburger J, Pfannmueller B, et al. Minimally invasive mitral valve surgery: "The Leipzig

Cite this article as: Kim J, Yoo JS. Totally endoscopic mitral valve repair using a three-dimensional endoscope system: initial clinical experience in Korea. J Thorac Dis 2020;12(3):705-711. doi: $10.21037 /$ jtd.2019.12.126 experience". Ann Cardiothorac Surg 2013;2:744-50.

13. Liang $H$, Liang $W$, Lei $Z$, et al. Three-Dimensional Versus Two-Dimensional Video-Assisted Endoscopic Surgery: A Meta-analysis of Clinical Data. World J Surg 2018;42:3658-68.

14. Westhofen S, Conradi L, Deuse T, et al. A matched pairs analysis of non-rib-spreading, fully endoscopic, miniincision technique versus conventional mini-thoracotomy for mitral valve repair. Eur J Cardiothorac Surg 2016;50:1181-7.

15. Zdichavsky M, Schmidt A, Luithle T, et al. Threedimensional laparoscopy and thoracoscopy in children and adults: A prospective clinical trial. Minim Invasive Ther Allied Technol 2015;24:154-60.

16. Mercante G, Battaglia P, Manciocco V, et al. Threedimensional minimally invasive video-assisted thyroidectomy: preliminary report. J Exp Clin Cancer Res 2013;32:78. 